Article

\title{
Immobilization of $\beta$-CD on a Hyper-Crosslinked Polymer for the Enhanced Removal of Amines from Aqueous Solutions
}

\author{
Zujin Yang ${ }^{1,2}, * \mathbb{C}$, Guifang $\mathrm{Wu}^{1}$, Qiuru $\mathrm{Li}^{1}$, Hongxia $\mathrm{Ai}^{3}$, Xingdong Yao ${ }^{4}$ \\ and Hongbing $\mathrm{Ji}$ 2,3,5,*(D) \\ 1 School of Chemical Engineering and Technology, Sun Yat-Sen University, Zhuhai 519082, China; \\ Wugf5@mail2.sysu.edu.cn (G.W.); Liqr@mail2.sysu.edu.cn (Q.L.) \\ 2 School of Chemical Engineering, Huizhou Research Institute of Sun Yat-Sen University, \\ Huizhou 516216, China \\ 3 Fine Chemical Industry Research Institute, The Key Laboratory of Low-carbon Chemistry \& Energy \\ Conservation of Guangdong Province, School of Chemistry, Sun Yat-Sen University, Guangzhou 510275, \\ China; aihongxia@mail.sysu.edu.cn \\ 4 The Key laboratory of Forest Chemistry \& Engineering of Guangxi, Guangxi University for Nationalities, \\ Nanning 210000, China; yaoxingdong@gxun.edu.cn \\ 5 School of Chemical Engineering, Guangdong University of Petrochemical Technology, \\ Maoming 525000, China \\ * Correspondence: yangzj3@mail.sysu.edu.cn (Z.Y.); jihb@mail.sysu.edu.cn (H.J.)
}

Received: 22 June 2020; Accepted: 16 July 2020; Published: 21 July 2020

\begin{abstract}
In this paper, we adopted a simple and efficient strategy to prepare a $\beta$-cyclodextrin $(\beta-C D)$-modified hyper-crosslinked polymer (CDM-HCP). The structures and physicochemical properties of the as-synthesized polymer were also evaluated. It was applied to the removal of anilines from aqueous solutions. The introduction of $\beta$-CD into the hyper-crosslinked polymer significantly enhanced adsorption properties for the removal of various amines. The adsorption kinetics agreed with the pseudo-second-order mode very well. The adsorption isotherm data of $p$-methylaniline ( $p$-MA) and $p$-aminobenzoic acid $(p-\mathrm{ABC})$ were in agreement with the Langmuir isotherm, whereas aniline and $p$-chloroaniline $(p-C A)$ were fitted best with the Freundlich model. The maximum adsorption capacities $\left(q_{\max }\right)$ determined by adsorption isotherms were $148.97 \mathrm{mg} / \mathrm{g}$ for aniline, $198.45 \mathrm{mg} / \mathrm{g}$ for $p$-MA, $293.71 \mathrm{mg} / \mathrm{g}$ for $p$-CA, and $622.91 \mathrm{mg} / \mathrm{g}$ for $p$-ABC, respectively. It had higher adsorption capacities than those of some commercial polymeric resins, such as XAD-4, PA66, and AB-8. The interaction mechanism was investigated by FTIR, XPS, and the ONIOM2 method. A CDM-HCP can be regenerated efficiently and used repeatedly, indicating its potential technological applications in removing organic pollutants from actual industrial effluents.
\end{abstract}

Keywords: CDM-HCP; adsorption; amines; hyper-crosslinked polymer; interaction mechanism

\section{Introduction}

In recent years, the development of industrialization and urbanization has aroused global attention to environmental pollution. Organic pollutants in most developing countries have no effective treatment and are directly discharged into the environment during the production process, including the petroleum, chemical, pharmaceutical, textile, and plastics industries. Health and environmental issues have stemmed from them because of their high toxicity and difficult degradation [1,2]. Anilines are applied as intermediates in the production of pesticides, drugs, dyes, rubber, and herbicides $[3,4]$. Anilines are one kind of significant organic pollutants in our environment, and the discharge of these 
contaminants may cause great harm to the environment and the drinking water even when they exist as a trace [5]. For example, the US Environmental Protection Agency (EPA) suggests that the maximum acceptable concentration of aniline in water is $0.262 \mathrm{ppm}$ [6]. For the sustainable development of the water environment, it is of significance to develop efficient ways for the removal of toxic organic substances in wastewaters. Various treatment methods such as biodegradation, photocatalytic degradation, ozonation oxidation, and adsorption have been employed to eliminate anilines from wastewaters [7-9]. Among these methods, adsorption is one of the most effective approaches to remove these pollutants because it has certain advantages, such as low cost, simplicity, and effectiveness.

A hyper-crosslinked polymer (HCP) is an efficient adsorbent for the removal of anilines because of specific surface areas, porous structures, and surface physicochemical characteristics [10-12]. The Friedel-Crafts reaction has been used to synthesize HCPs by using low crosslinked chloromethylated polystyrene (CM-PS) as a starting skeleton in the presence of Lewis acids in solution. A previous publication has shown that the as-synthesized HCP shows low equilibrium capacity for the polar compounds due to hydrophobic surface [13]. Chemical modification has been considered to introduce different functional groups such as $-\mathrm{OH},-\mathrm{NH}_{2}$, and $-\mathrm{COOH}$ into the polymers, which can increase the adsorption capacity for poisonous organic chemicals. Therefore, HCPs modified with polar components have been studied during the past decades $[11,12,14,15]$.

Cyclodextrins (CDs), which include 6-8 $\alpha$-(1-4)-linked $\alpha$-D-glucopyranose units to form a hydrophobic center and hydrophilic edge, are a class of natural cyclic oligosaccharides derived from starch (named $\alpha-, \beta$-, and $\gamma$-CD, respectively) $[16,17]$. CDs can form inclusion complexes via the weak interactions with aromatic compounds in aqueous solutions $[18,19] . \beta-\mathrm{CD}$ is one of the cheapest and most extensively used CDs, and it is conducive to the removal of polar aromatic compounds from wastewaters through the host-guest interactions between adsorbent and adsorbate. However, there is an obvious deficiency in the application of $\beta$-CD due to its solubility, and immobilization on certain supports to realize its recyclability is an ideal method. $\beta$-CD-based materials have been applied in removing organic pollutants such as aromatics or phenolics from the environment [20,21]. Li et al. [22] constructed a hyper-crosslinked $\beta$-CD porous polymer by crosslinking benzylated $\beta$-CD with dichloroxylene via a Friedel-Crafts reaction, which has a high surface area and good thermal stability with an adsorption capacity of $278 \mathrm{mg} / \mathrm{g}$ for bisphenol A at $25^{\circ} \mathrm{C}$. Dai et al. [23] also synthesized a $\beta$-CD-based $\mathrm{HCP}$ by reacting benzylated $\beta$-CD with formaldehyde dimethyl acetal, and an exceptional adsorption performance was observed for the removal of aromatic compounds in aqueous solutions. However, their industrial applications have been limited by the complex preparation process and the use of large organic solvents. Developing an adsorbent with high efficiency and low cost is urgent for the implementation of this process.

In this work, we first used a facile Friedel-Crafts alkylation reaction to synthesize a $\beta$-CD-based hyper-crosslinked polymer (CDM-HCP) (Figure 1). The structure analysis of the as-synthesized CDM-HCP was carried out with some structural characterization, and the CDM-HCP showed strong preferential adsorption toward anilines from water. Adsorption kinetics and aniline isotherms onto the CDM-HCP were also tested. The interaction mechanism between adsorbent and adsorbate was also proposed based on XPS, FTIR analyses, and quantum chemical calculations. 

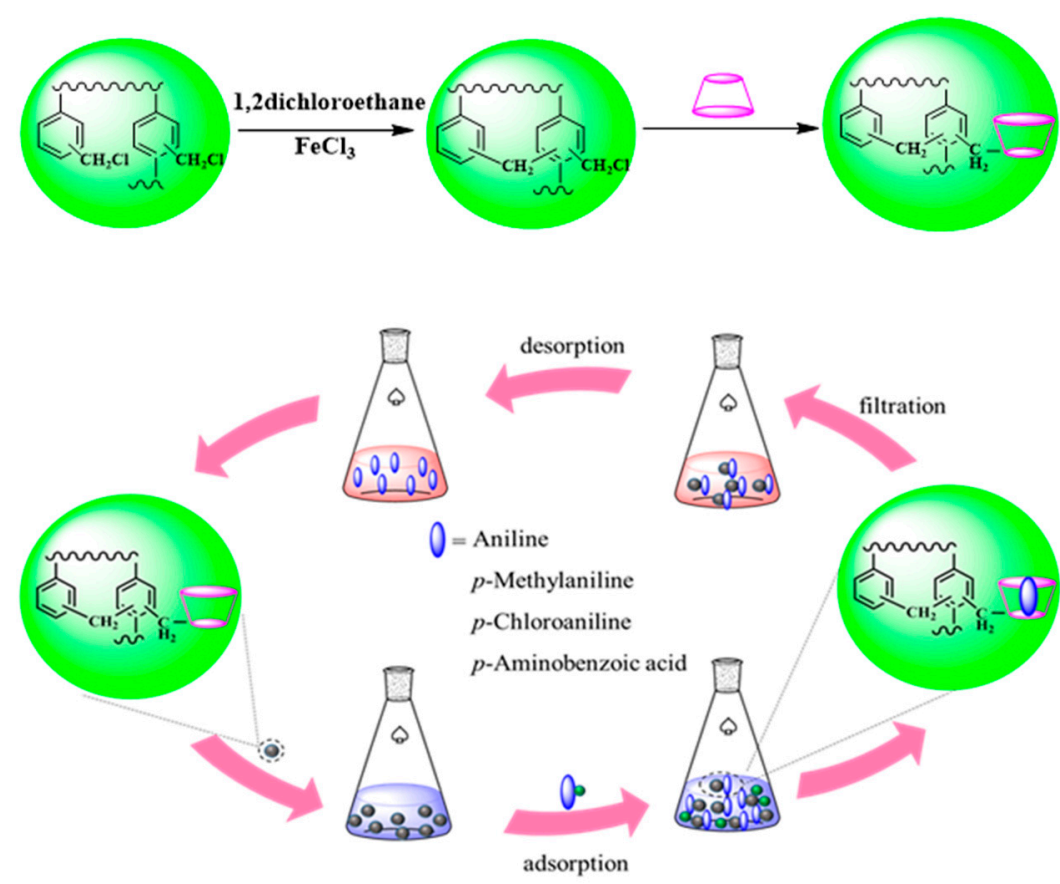

Figure 1. Schematic presentation for the synthesis of a $\beta$-cyclodextrin-modified hyper-crosslinked polymer (CDM-HCP) and the adsorption process of amines.

\section{Materials and Methods}

\subsection{Chemicals}

$\beta$-Cyclodextrin ( $\beta$-CD, purity $>99 \%$ ) was supplied from Shanghai Boao Biotechnology (Shanghai, China). Chloromethylated polystyrene (CM-PS) beads (crosslinked with $8 \%$ divinylbenzene (DVB), $18 \%$ chlorine content) were obtained from Nankai Chemical Co., Ltd. (Tianjin, China). All the other reagents used were at least of analytical grade. Distilled water was used from the Millipore water purification system.

\subsection{Synthesis of the CDM-HCP}

As shown in Figure 1, the CDM-HCP was prepared based on a previous synthesis procedure [24]. First, a $10 \mathrm{~g}$ portion of CM-PS beads was put into $50 \mathrm{~mL}$ of 1,2-dichloroethane (DCE) to soak overnight. Under mechanical stirring, $1.2 \mathrm{~g}$ of $\mathrm{FeCl}_{3}\left(-\mathrm{CH}_{2} \mathrm{Cl}\right.$ : $\left.\mathrm{FeCl}_{3}=1: 1\right)$ was completely dissolved in the reaction mixture. Then, the solution was heated to $115^{\circ} \mathrm{C}$ and kept at the same temperature for $12 \mathrm{~h}$ under $\mathrm{N}_{2}$ protection. After being cooled to $25^{\circ} \mathrm{C}$, the $\mathrm{CDM}-\mathrm{HCP}$ was separated and washed with $1 \%$ aqueous hydrochloric acid $(w / w)$ and distilled water, respectively, until $\mathrm{pH}$ was neutral. After the reaction, the CDM-HCP was extracted in a Soxhlet extractor (Shanghai Hongji Instrument Co., Ltd. Shanghai, China) using ethanol as solvent for $24 \mathrm{~h}$. Finally, the hyper-crosslinked polymer (HCP) was dried in a vacuum oven at $80^{\circ} \mathrm{C}$ for $12 \mathrm{~h}$.

To prepare the CDM-HCP, $1.0 \mathrm{~g}$ of $\beta$-CD and $25 \mathrm{~mL} \mathrm{~N}$ N-dimethyl formamide with the appropriate amount of organic base were put into a $50 \mathrm{~mL}$ round-bottomed flask. Then, a $2.5 \mathrm{~g}$ portion of dry $\mathrm{HCP}$ was swollen in the mixture, heated to $90^{\circ} \mathrm{C}$, and kept at the same temperature for $12 \mathrm{~h}$. Finally, the resulting CDM-HCP was filtered, washed with deionized water and $\mathrm{MeOH}$, and dried under vacuum at $90^{\circ} \mathrm{C}$ for $6 \mathrm{~h}$ to obtain the product.

\subsection{Adsorbent Characterization}

As described in a previously reported study [25], an ion chromatographic method was used to determine the chlorine content in the polymers. $\mathrm{pH}$ values were obtained by using a PHS-3C 
$\mathrm{pH}$ meter (Inesa, Beijing, China). The structure of the polymers was analyzed with a TENSOR 37 Fourier transform spectrometer (Bruker, Ettlingen, Germany). A Netzsch STA-449C thermal analysis system (Netzsch Corporation, Selb, Germany) was used to calculate the weight loss of the CDM-HCP. A specific surface area and pore size analyzer (Micromeritics Instrument Corporation, Norcross, GA, USA) was applied to measure the Brunauer-Emmett-Teller (BET) surface area and pore distribution of the polymers. XPS spectra (Thermo, Pleasanton, CA, USA) were recorded on an ESCALAB 250XI X-ray photoelectron spectroscope equipped with X-ray monochromatization (ESCALAB 250, Thermo Electron, Altrincham, UK). Surface properties of the polymers in aqueous phase were detected by a contact angle measuring system (OCA20, DataPhysics, Filderstadt, Germany).

\subsection{Adsorption Experiments}

Adsorption properties of the CDM-HCP for anilines were performed at the initial $\mathrm{pH} 7.0$ for each aniline. A $0.1 \mathrm{~g}$ portion of the CDM-HCP was put into $100 \mathrm{~mL}$ of aniline solution with an initial concentration of $1000 \mathrm{mg} / \mathrm{L}$. The adsorption reached equilibrium at a constant speed of $200 \mathrm{rpm}$ at $20^{\circ} \mathrm{C}$, and the $\mathrm{CDM}-\mathrm{HCP}$ was separated by vacuum filtration. The final concentration of anilines was analyzed using a UV-Vis spectrometer (Shimadzu UV-2450, Kyoto, Japan), and the adsorption capacity of the anilines was calculated as follows:

$$
q_{e}=\frac{\left(C_{i}-C_{e}\right) V_{0}}{m}
$$

where $q_{e}$ is the amount of anilines adsorbed per $\mathrm{g}$ of adsorbent $(\mathrm{mg} / \mathrm{g}) ; C_{i}$ is the initial concentration of anilines $(\mathrm{mg} / \mathrm{L}) ; C_{e}$ is the equilibrium concentration of anilines in solution $(\mathrm{mg} / \mathrm{L}), V_{0}$ is the volume of the initial solution $(\mathrm{mL})$; and $m$ is the dry weight of the CDM-HCP $(\mathrm{g})$. We further studied the effect of different $\beta$-CD contents $(0-80 \mu \mathrm{mol} / \mathrm{g})$, ionic strength $\left(\mathrm{C}_{\mathrm{NaCl}}=0-0.5 \mathrm{~mol} / \mathrm{L}\right), \mathrm{pH}(3.0-11.0)$, adsorption kinetics (0-800 $\mathrm{min})$, and adsorption isotherms $(100-1000 \mathrm{mg} / \mathrm{L})$ of anilines at different temperatures.

\subsection{Desorption and Regeneration Experiments}

The method of desorption and regeneration experiments was carried out according to previous studies $[26,27]$. When the adsorption attained saturation, the CDM-HCP was desorbed with $\mathrm{MeOH}$ and water, respectively, to remove residual $\mathrm{MeOH}$. In all the desorption tests, the tested samples were measured using a UV-Vis spectrometer. The gel adsorbent was reused five times under similar adsorption conditions. The concentration of residual anilines in the filtrate was determined, and the adsorption capacity of each aniline at an interval were calculated with Equation (1).

\subsection{Computational Chemistry Calculations}

The inclusion formation of the CDM-HCP and anilines is shown in Figure 2. Aniline, $p$-MA, $p$ - $\mathrm{CA}$, and $P-\mathrm{ABC}$ are included by $\beta-\mathrm{CD}$ moiety in the $\mathrm{CDM}-\mathrm{HCP}$, and the adsorption performance of the CDM-HCP is not different from the property of the $\beta$-CD molecule, which is in agreement with previous studies [28-30]. The Gaussian 09 software package (Gaussian, Inc., Wallingford, CT, USA) was used to perform these theoretical calculations, which are shown in the Supplementary Materials (Computational methods). 

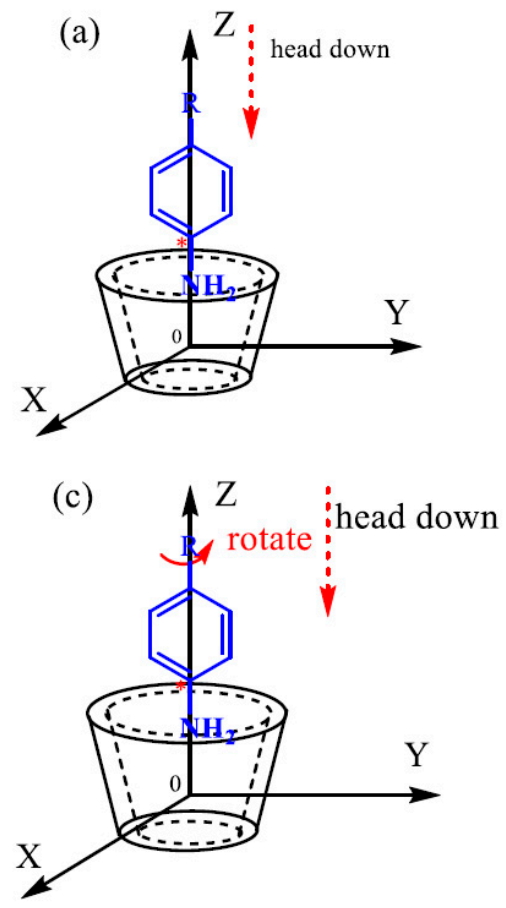

$$
\mathrm{R}=\mathrm{H}, \mathrm{Cl}, \mathrm{CH}_{3} \text {, and } \mathrm{COOH}
$$
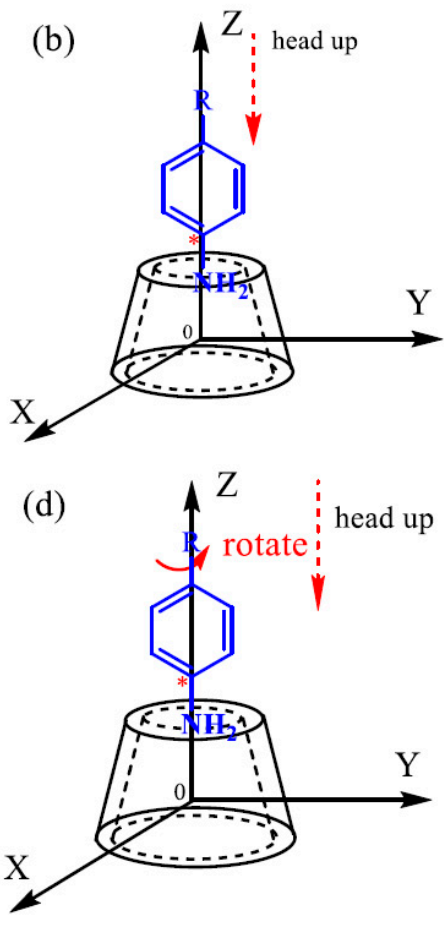

Figure 2. Inclusion processes of $\beta$-CD with guests: (a) head down, (b) head up of $\beta$-CD with anilines for steps; (c) head down, (d) head up of $\beta$-CD with anilines for dihedral angles.

\section{Results and Discussion}

\subsection{Characterization of the CDM-HCP}

The CDM-HCP was obtained by the reaction of the swollen CM-PS with $\beta$-CD in DCE in the presence of anhydrous $\mathrm{FeCl}_{3}$. SEM images of the CM-PS and CDM-HCP show that CM-PS has a smooth spherical surface. After being modified by $\beta-\mathrm{CD}$, the CDM-HCP still retains spherical structure. However, its surface becomes rough and large crystalline particles of rather irregular size were observed on the surface of the CDM-HCP (Figure S1 (Supplementary Materials)). Figure 3 shows that the characteristic bands at 1270 and $670 \mathrm{~cm}^{-1}$ are due to the $\mathrm{C}-\mathrm{Cl}$ stretching vibration of the CM-PS's $\mathrm{CH}_{2} \mathrm{Cl}$ groups (Figure 3a) [31]. After the Friedel-Crafts alkylation reaction, the adsorption peak at $1270 \mathrm{~cm}^{-1}$ is significantly weakened for HCP (Figure 3b). In addition, the CM-PS's chlorine content decreases from $18.01 \%$ to $4.32 \%$ (HCP). The results indicate that the CM-PS's C-Cl groups could be involved in the reaction and transformed to $-\mathrm{CH}_{2}$ - groups. The results are in agreement with previous studies [32,33]. The bands at 3380 and $1030 \mathrm{~cm}^{-1}$ are due to $-\mathrm{OH}$ and $\mathrm{C}-\mathrm{O}$ groups of $\beta-\mathrm{CD}$ [34] (Figure 3c). After the reaction of the HCP with $\beta-C D$, the band at $1030 \mathrm{~cm}^{-1}$ appears in the CDM-HCP's FTIR spectrum, and the bands at 1270 and $670 \mathrm{~cm}^{-1}$ nearly disappear, implying that the residual chlorine on the $\mathrm{HCP}^{\prime} \mathrm{s}$ surface could be substituted by $\beta$-CD. In addition, the $\mathrm{HCP}^{\prime}$ s chlorine content further decreases to $0.24 \%$ and the adsorption band $3380 \mathrm{~cm}^{-1}$ was increased by increasing the content of $\beta-C D$ (Figure $3 \mathrm{~d}$ ), suggesting that $\beta$-CD exited in HCP [33]. In addition, Figure S2 (Supplementary Materials) shows the XPS wide scan of the HCP and CDM-HCP, respectively. In comparison with the $\mathrm{HCP}$, the $\mathrm{O}_{1 \mathrm{~s}}$ peak of the CDM-HCP was observed at $532.50 \mathrm{eV}$, whereas the $\mathrm{Cl}_{2 \mathrm{p}}$ peak of the $\mathrm{HCP}$ nearly disappeared. For the C1s spectrum of the CDM-HCP in Figure S2 (Supplementary Materials), different valence states of carbon were present on the HCP's surface, and the peaks at 284.7 and $285.1 \mathrm{eV}$ were due to the presence of $\mathrm{C}=\mathrm{C}$ and $\mathrm{C}-\mathrm{O}$ of $\beta-\mathrm{CD}$, respectively, indicating the successful immobilization of $\beta-\mathrm{CD}$ in $\mathrm{HCP}$ [35]. 


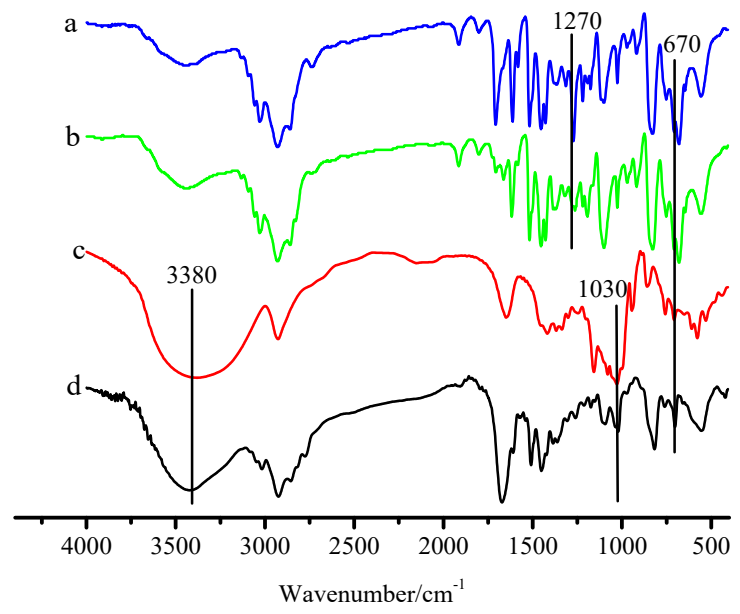

Figure 3. FTIR of crosslinked chloromethylated polystyrene (CM-PS) (a), HCP (b), $\beta$-CD (c), and CDM-HCP (d).

Further analysis by TG (Figure S3 (Supplementary Materials)) showed that the CDM-HCP has good thermal stability with a thermal decomposition temperature of $375-400{ }^{\circ} \mathrm{C}$ due to its highly crosslinked network [36]. Such a high thermal stability is very conducive to adsorption and regeneration of the CDM-HCP in industrial applications. Figure 4 illustrates the $\mathrm{N}_{2}$ adsorption-desorption isotherms and pore-size distribution for the CDM-HCP. The raw material CM-PS is nonporous when it is in a dry state, but it could produce macropores after swelling in DCE, making the $-\mathrm{CH}_{2} \mathrm{Cl}$ groups to be extended completely. It is attributed that they would have an electrophilic substitution with the neighboring benzene rings, inducing abundant rigid methylene crosslinking bridges, which would produce these macropores after drying (Figure 4a). The results indicate that the Friedel-Crafts reaction could result in higher BET surface area and pore volume. After adding $\beta$-CD to the reaction, the $\mathrm{N}_{2}$ capacity decreases quickly, implying that the BET surface area decreases and some micropores mostly in the range of 20-50 nm exist in the CDM-HCP (Figure S2b and Table S1 (Supplementary Materials)). This result indicates that the HCP's surface pores are turned into micropores with the addition of functional groups [37]. Table S1 (Supplementary Materials) indicates that the O content of the CDM-HCP is 6.79\%, which may be due to the introduction of $\beta-\mathrm{CD}$, resulting in an increase in oxygen functional groups. In addition, its lower contact angle $\left(108^{\circ}\right)$ was observed in comparison to that of the HCP $\left(142^{\circ}\right)$. The results show that the addition of $\beta$-CD into the HCP increases its hydrophilicity, implying that the $-\mathrm{OH}$ groups of $\beta-\mathrm{CD}$ are uploaded onto the surface of the hole in the HCP.
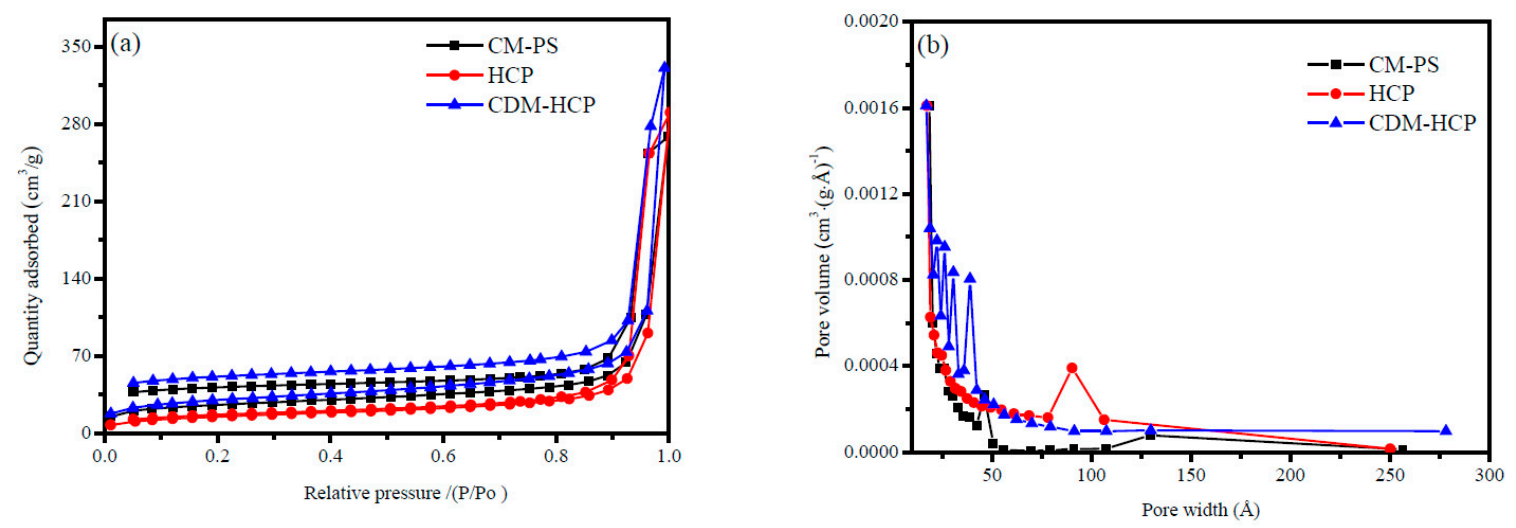

Figure 4. Adsorption-desorption isotherms (a) of $\mathrm{N}_{2}$ at $77 \mathrm{~K}$ and pore-size distribution (b) of CM-PS, $\mathrm{HCP}$, and CDM-HCP. 


\subsection{Adsorption Performance of the CDM-HCP}

Figure 5 shows that $q_{e}$ was increased with increasing amounts of $\beta$-CD up to $14.28 \mu \mathrm{mol} \cdot \mathrm{g}^{-1}$. However, $q_{e}$ decreased when the amounts of $\beta$-CD exceeded $14.28 \mu \mathrm{mol} \cdot \mathrm{g}^{-1}$. It was due to the high $\beta$-CD loading amounts, which led to the non-uniformity of the particle size distribution of the CDM-HCP, decreasing the mass transfer of the anilines.

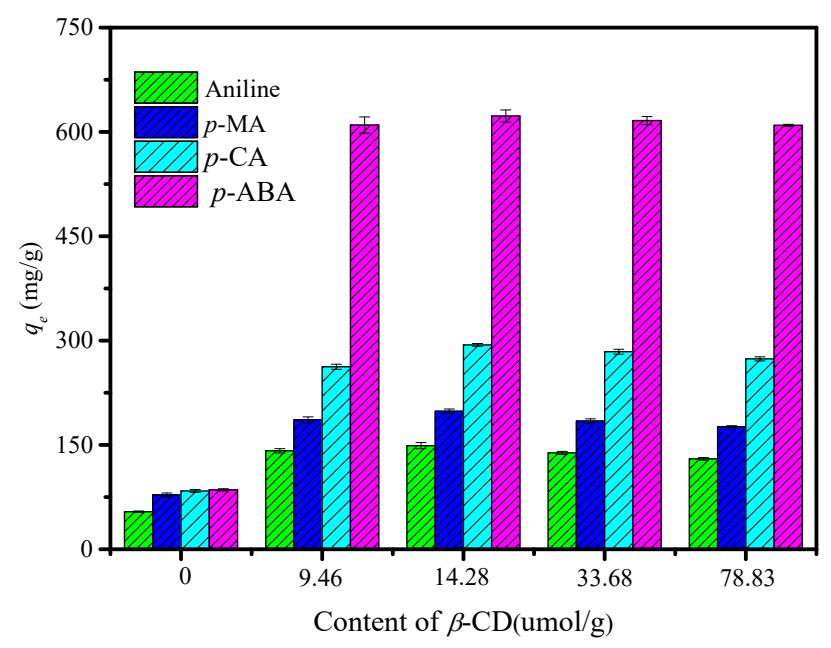

Figure 5. Effect of the amounts of $\beta$-CD on the aniline adsorption of the CDM-HCP.

Figure 6 shows that the changes in ionic strength had no significant effects on the adsorption of anilines, demonstrating that the CDM-HCP has high stability within a wide range of ionic strength. $q_{e}$ slightly decreased with increasing $\mathrm{NaCl}$ concentration in the range of 0.1 to $0.5 \mathrm{~mol} \cdot \mathrm{L}^{-1}$. It may be that the solubility of adsorbate will increase significantly with increasing electrolyte concentration due to the salt effect, weakening the adsorption capacity of the adsorbent.

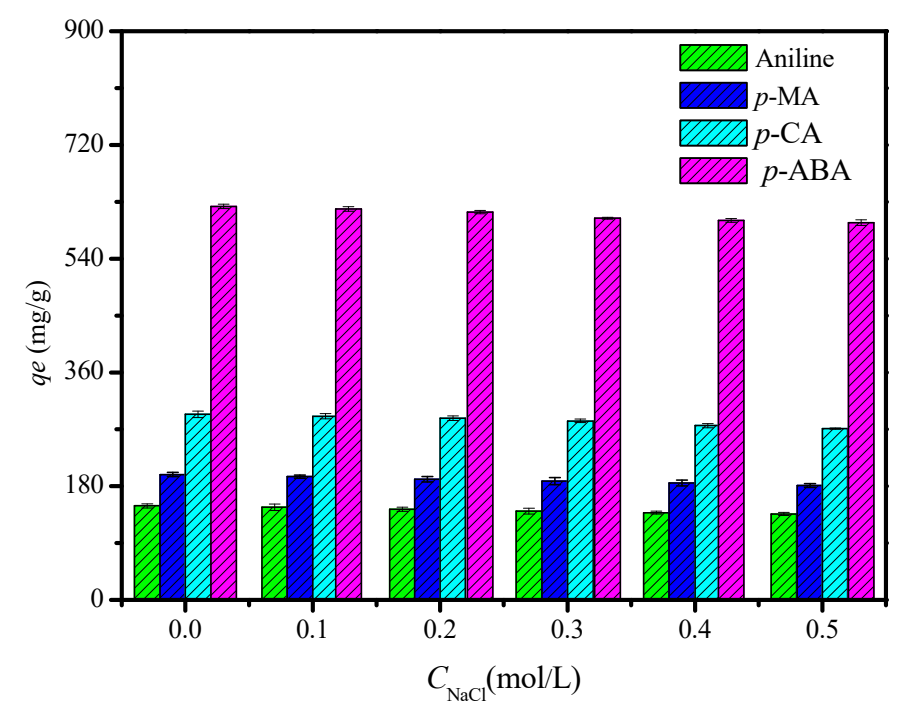

Figure 6. Influence of $\mathrm{NaCl}$ concentration on aniline removal using the CDM-HCP as adsorbent.

The solution's $\mathrm{pH}$ is an important factor affecting the adsorption of anilines on the CDM-HCP. The influence of $\mathrm{pH}$ on the aniline adsorption by the CDM-HCP was studied in a $\mathrm{pH}$ range of 3 to 11. Aniline adsorption was obviously affected by the solution's $\mathrm{pH}$, which affected the surface charge of the adsorbent and the ionization degree and speciation of the adsorbate. As shown in Figure 7, when the solution's $\mathrm{pH}$ was less than or equal to $4, q_{e}$ for the anilines in the aqueous phase was 
extremely low, which was probably because the cyclodextrin molecules were hydrolyzed under acidic conditions and their structure was destroyed, decreasing the adsorption capacity. When $\mathrm{pH}$ was from 5 to 7 , the adsorption capacity of the CDM-HCP rose significantly for the anilines. In this case, the adsorbate existed in a molecular state, which facilitates the interaction with the functional groups of the CDM-HCP and had a maximum $q_{e}$ of about $\mathrm{pH}$ 7. However, higher solution $\mathrm{pH}$ also decreased the uptake of anilines. It may be due to the formation of soluble hydroxyl complexes by decreasing the free ions. The optimum $\mathrm{pH}$ values were 7.0 for aniline, 7.0 for $p$-MA, 6.0 for $p$-CA, and 6.0 for $p$-ABC.

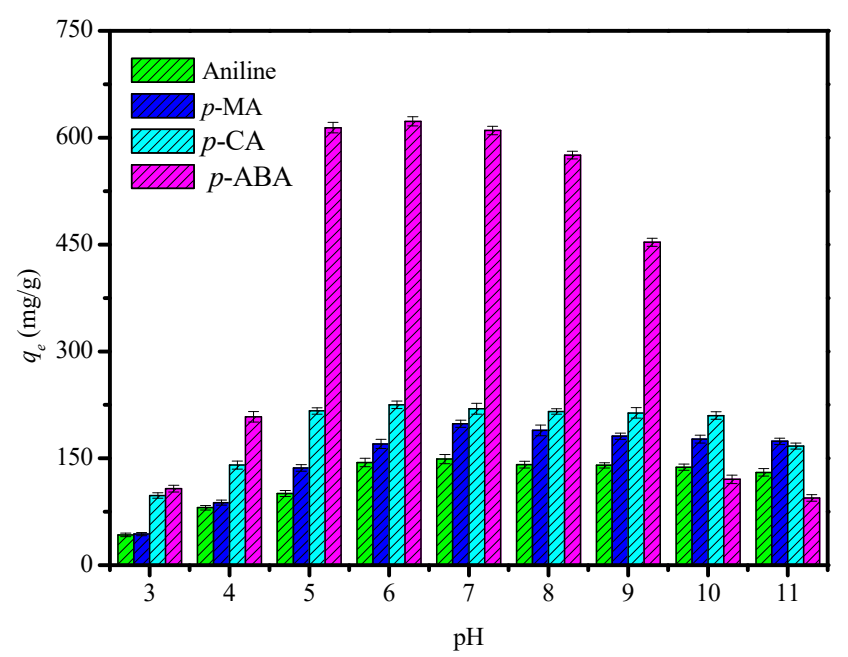

Figure 7. Effect of $\mathrm{pH}$ on the adsorption of anilines by the CDM-HCP.

\subsection{Adsorption Kinetics}

Figure 8 displays adsorption kinetic curves of anilines on the CDM-HCP versus the contact time at $20^{\circ} \mathrm{C}$. As shown in Figure 8, $q_{e}$ increased significantly within $200 \mathrm{~min}$ and then increased slowly in the subsequent step until reaching equilibrium after $600 \mathrm{~min}$. A further increase of contact time was insignificant for the equilibrium $q_{e}$ of adsorbate. This may be due to the fact that the active adsorption sites were sufficient at the beginning of adsorption, and decreased with the increment of adsorption time. Therefore, the adsorption time of $600 \mathrm{~min}$ was sufficient to attain equilibrium for the CDM-HCP in the aniline adsorption, which was selected for the further experiments.

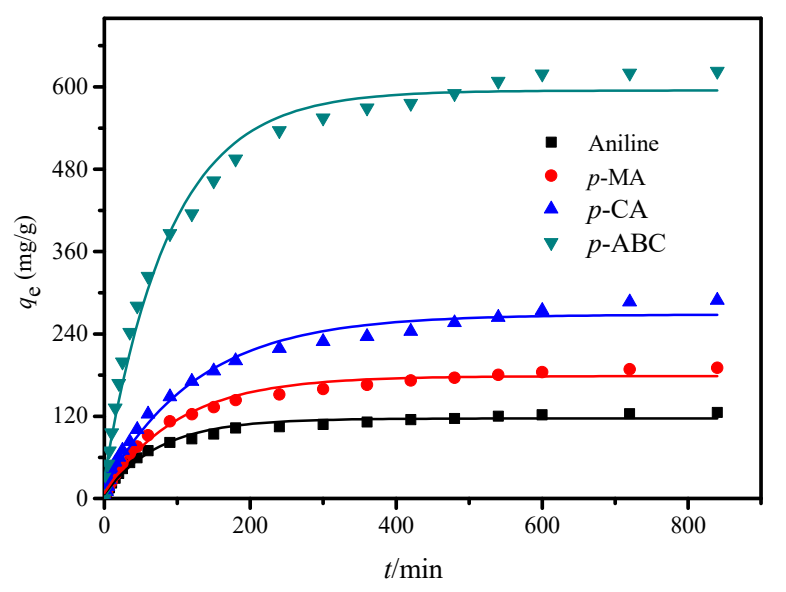

Figure 8. Adsorption kinetics of anilines on the CDM-HCP.

The fit of the experimental data to the pseudo-first-order, pseudo-second-order, and intraparticle diffusion models for the CDM-HCP was performed in Figure S4, and the calculated kinetic parameters are summarized in Table 1. 
Table 1. Kinetic parameters for the adsorption of aniline compounds on the CDM-HCP at $20^{\circ} \mathrm{C}$.

\begin{tabular}{cccccc}
\hline \multirow{2}{*}{ Model } & \multirow{2}{*}{ Parameter } & \multicolumn{4}{c}{ Adsorbate } \\
\cline { 3 - 5 } & & Aniline & $p$-MA & $p$-CA & $p$ - $A B C$ \\
\hline \multirow{2}{*}{ this study } & $C_{0}(\mathrm{mg} / \mathrm{L})$ & 1000 & 1000 & 1000 & 1000 \\
& $q_{\mathrm{e}, \text { expt }}(\mathrm{mg} / \mathrm{g})$ & 148.97 & 198.45 & 293.71 & 622.91 \\
pseudo-first-order & $k_{1}\left(\mathrm{~min}^{-1}\right)$ & $4.80 \times 10^{-3}$ & $5.00 \times 10^{-3}$ & $4.90 \times 10^{-3}$ & $2.52 \times 10^{-3}$ \\
& $q_{\mathrm{e}, \text { calcd }}(\mathrm{mg} / \mathrm{g})$ & 142.61 & 192.59 & 291.58 & 657.69 \\
pseudo-second-order & $R^{2}$ & 0.97 & 0.98 & 0.97 & 0.92 \\
& $k_{2}(\mathrm{~g} /(\mathrm{mg} / \mathrm{min}))$ & $1.54 \times 10^{-4}$ & $6.75 \times 10^{-5}$ & $3.73 \times 10^{-5}$ & $2.24 \times 10^{-5}$ \\
& $q_{\mathrm{e}, \text { calcd }}(\mathrm{mg} / \mathrm{g})$ & 130.89 & 204.50 & 309.60 & 684.93 \\
intraparticle diffusion & $R^{2}$ & 0.99 & 0.99 & 0.99 & 0.99 \\
& $k_{\text {int }}\left(\mathrm{g} /\left(\mathrm{mg} \cdot \mathrm{min}^{1 / 2}\right)\right)$ & 2.18 & 4.00 & 7.02 & 13.92 \\
& $k_{\mathrm{d}}$ & 67.85 & 85.04 & 99.44 & 279.07 \\
\hline
\end{tabular}

The results indicated that the correlation coefficient of the pseudo-second-order kinetic model $\left(R^{2}>0.99\right)$ was higher than that of the pseudo-first-order kinetic model $\left(R^{2}<0.99\right)$, implying that the adsorption process was more consistent with the second-order kinetic model. The results showed that the adsorption process may involve the mechanism of chemisorption. Furthermore, the theoretical calculated values $\left(q_{\mathrm{e}, \mathrm{cal}}\right)$ obtained from the pseudo-second-order model were in good agreement with the experimental values $\left(q_{e, e x p}\right)$, indicating the validity of the model to the adsorption system. According to the intraparticle diffusion model, $q_{t}$ to $t^{1 / 2}$ is not a straight line through the origin, showing that internal diffusion is not the mail-limiting mechanism for the aniline adsorption. Adsorption of anilines onto the CDM-HCP is divided into three steps as follows: diffusion of anilines to the external surface of the CDM-HCP; diffusion of anilines into the pores of the CDM-HCP; and adsorption of anilines onto the active sites of the CDM-HCP. Similar results have been reported for the adsorption of organic pollutants [38].

\subsection{Adsorption Isotherm}

An adsorption isotherm can be used to clarify the interaction mechanism between adsorbent and adsorbate. Langmuir, Freundlich, and Dubinin-Radushkevich (D-R) models were applied to study the saturated adsorption behavior and capacity (Supplementary Materials). Adsorption isotherms of anilines and initial aniline concentrations in the ranges of $100-1000 \mathrm{mg} / \mathrm{L}$ at 20,25 , and $30^{\circ} \mathrm{C}$ are displayed in Figure 9. The isotherm parameters and correlation coefficient $\left(R^{2}\right)$ are listed in Table 2.

The adsorption equilibrium was significantly affected by the initial concentrations of anilines at the different temperatures. $q_{e}$ quickly increased with the increase of initial concentrations until reaching equilibrium. In addition, $q_{e}$ onto the $\mathrm{CDM}-\mathrm{HCP}$ obviously decreased with rising temperature, implying that this is of an exothermic nature [39]. The $q_{\max }(\mathrm{mg})$ values of aniline, $p$-MA, $p$-CA, and $P$-ABC calculated from the Langmuir model were $163.25,225.44,291.50$, and $752.81 \mathrm{mg} / \mathrm{g}$ at $20^{\circ} \mathrm{C}$, respectively (Table 2). From $R^{2}$, the Langmuir isotherm model demonstrated a better application to the adsorption of $p$-MA and $p-\mathrm{ABC}$ onto the $\mathrm{CDM}-\mathrm{HCP}$, indicating their anchoring to the functional groups of the CDM-HCP with the formation of monolayer surface coverage. In contrast, aniline and $p$-CA obeyed the Freundlich isotherm model better, indicating that this model was used to characterize the equilibrium adsorption with multilayer adsorption. Previous results indicated that if $1<n<10$, the adsorption can occur smoothly, it is difficult to take place if $0.5<n<1$, and it cannot perform for $n<0.5$ for the Freundlich equation [40]. From Table 2, $n$ values calculated from the Freundlich equation are all in the range of 1.26 to 3.57 , implying that the CDM-HCP would be suitable for enriching the adsorption of anilines. The $E_{\mathrm{a}}$ value of the $\mathrm{D}-\mathrm{R}$ isothermal adsorption model is the main index to judge whether the adsorption is physisorption or chemisorption. From Table 2, the $E_{\mathrm{a}}$ values are all greater than $16 \mathrm{~kJ} / \mathrm{mol}$, showing that the adsorption process is chemisorption [41]. 

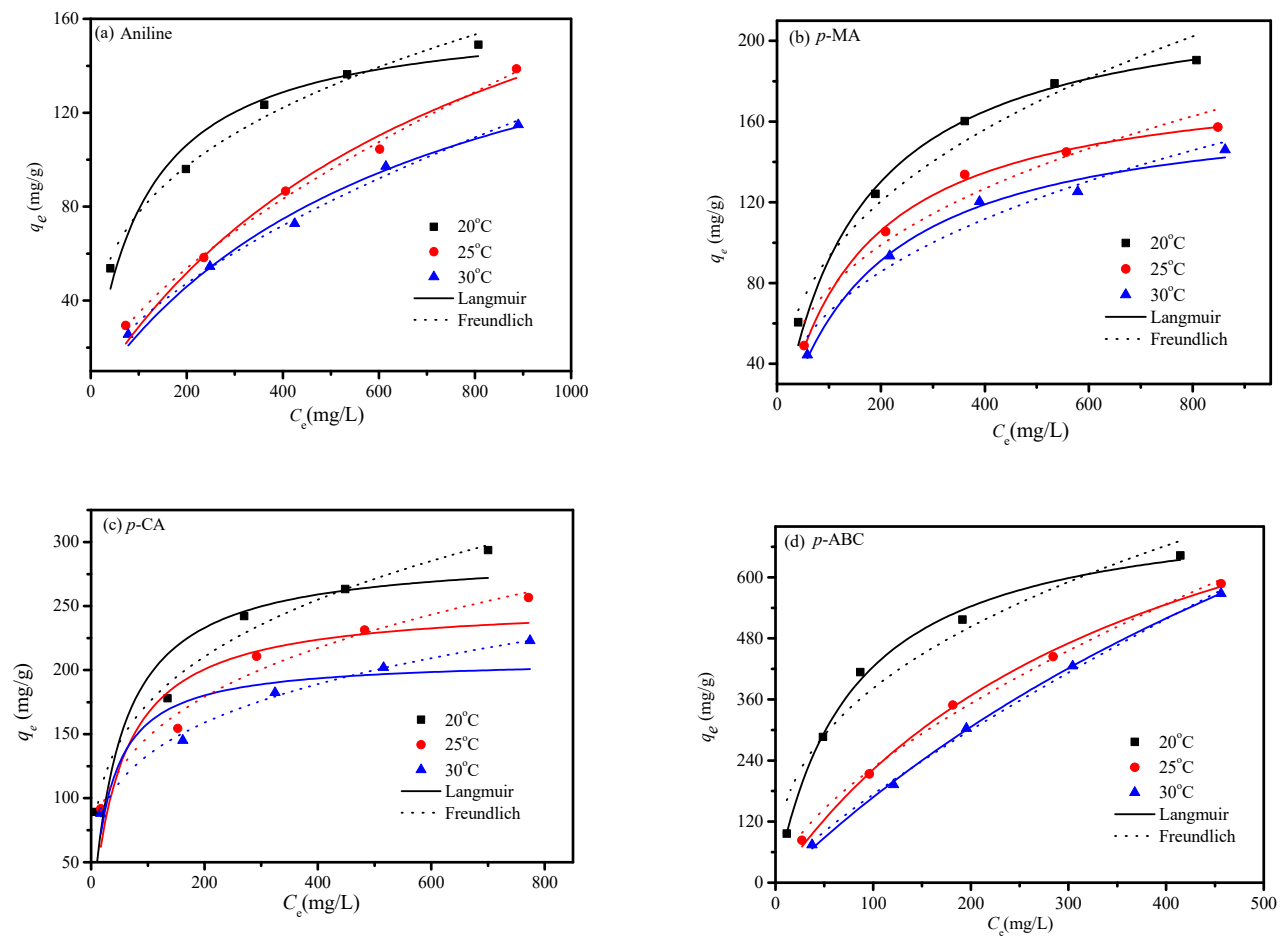

Figure 9. Isotherm model curves for the adsorption of aniline (a), $p$-MA (b), $p$-CA (c) and $p$-ABC (d) on the CDM-HCP; solid line is the Langmuir model and dashed line is the Freundlich model.

Table 2. Calculated parameters of Langmuir, Freundlich, and Dubinin-Radushkevich (D-R) Models for the adsorption of anilines.

\begin{tabular}{|c|c|c|c|c|c|c|}
\hline \multirow{2}{*}{ Model } & \multirow{2}{*}{ Temperature $/{ }^{\circ} \mathrm{C}$} & \multirow{2}{*}{ Parameter } & \multicolumn{4}{|c|}{ Adsorbate } \\
\hline & & & Aniline & $p$-MA & $p$-CA & $p-A B C$ \\
\hline \multirow{10}{*}{ Langmuir Model } & \multirow{3}{*}{20} & $K_{\mathrm{L}}(\mathrm{L} / \mathrm{mg})$ & $9.32 \times 10^{-3}$ & $6.84 \times 10^{-3}$ & $1.99 \times 10^{-3}$ & $1.29 \times 10^{-2}$ \\
\hline & & $q_{\max }(\mathrm{mg} / \mathrm{g})$ & 163.25 & 226.44 & 292.50 & 753.81 \\
\hline & & $R^{2}$ & 0.968 & 0.971 & 0.824 & 0.995 \\
\hline & \multirow{3}{*}{25} & $K_{\mathrm{L}}(\mathrm{L} / \mathrm{mg})$ & $1.31 \times 10^{-3}$ & $6.74 \times 10^{-3}$ & $1.98 \times 10^{-2}$ & $2.67 \times 10^{-3}$ \\
\hline & & $q_{\max }(\mathrm{mg} / \mathrm{g})$ & 152.93 & 183.54 & 254.13 & 666.40 \\
\hline & & $R^{2}$ & 0.993 & 0.996 & 0.838 & 0.998 \\
\hline & \multirow{3}{*}{30} & $K_{\mathrm{L}}(\mathrm{L} / \mathrm{mg})$ & $1.52 \times 10^{-3}$ & $5.74 \times 10^{-3}$ & $3.13 \times 10^{-2}$ & $7.08 \times 10^{-2}$ \\
\hline & & $q_{\max }(\mathrm{mg} / \mathrm{g})$ & 140.25 & 171.56 & 210.18 & 579.27 \\
\hline & & $R^{2}$ & 0.996 & 0.997 & 0.848 & 0.998 \\
\hline & \multirow{3}{*}{20} & $K_{\mathrm{f}}(\mathrm{L} / \mathrm{mg})$ & 1.71 & 16.62 & 48.74 & 61.42 \\
\hline \multirow{8}{*}{ Freundlich Model } & & $n$ & 3.03 & 2.70 & 3.57 & 2.50 \\
\hline & & $R^{2}$ & 0.995 & 0.994 & 0.982 & 0.945 \\
\hline & \multirow{3}{*}{25} & $K_{f}(\mathrm{~L} / \mathrm{mg})$ & 1.95 & 14.81 & 40.98 & 11.89 \\
\hline & & $n$ & 1.58 & 2.78 & 3.57 & 1.56 \\
\hline & & $R^{2}$ & 0.992 & 0.938 & 0.989 & 0.998 \\
\hline & \multirow{3}{*}{30} & $K_{f}(\mathrm{~L} / \mathrm{mg})$ & 1.90 & 11.28 & 22.48 & 24.67 \\
\hline & & $n$ & 1.64 & 2.61 & 4 & 1.26 \\
\hline & & $R^{2}$ & 0.996 & 0.959 & 0.998 & 0.997 \\
\hline \multirow{12}{*}{ D-R Model } & \multirow{4}{*}{20} & $\beta$ & $4.22 \times 10^{-4}$ & $2.89 \times 10^{-4}$ & $1.41 \times 10^{-5}$ & $3.99 \times 10^{-5}$ \\
\hline & & $q_{\mathrm{m}}(\mathrm{mg} / \mathrm{g})$ & 129.87 & 163.25 & 240.89 & 476.56 \\
\hline & & $E_{\mathrm{a}}(\mathrm{KJ} / \mathrm{mol})$ & 34.44 & 41.58 & 91.08 & 63.09 \\
\hline & & $R^{2}$ & 0.892 & 0.848 & 0.808 & 0.846 \\
\hline & \multirow{4}{*}{25} & $\beta$ & $1.15 \times 10^{-3}$ & $4.84 \times 10^{-4}$ & $4.36 \times 10^{-5}$ & $2.15 \times 10^{-4}$ \\
\hline & & $q_{\mathrm{m}}(\mathrm{mg} / \mathrm{g})$ & 97.46 & 135.75 & 210.67 & 396.24 \\
\hline & & $E_{\mathrm{a}}(\mathrm{KJ} / \mathrm{mol})$ & 21.45 & 32.69 & 78.13 & 49.47 \\
\hline & & $R^{2}$ & 0.725 & 0.918 & 0.737 & 0.768 \\
\hline & \multirow{4}{*}{30} & $\beta$ & $1.35 \times 10^{-3}$ & $6.26 \times 10^{-4}$ & $3.93 \times 10^{-5}$ & $4.15 \times 10^{-4}$ \\
\hline & & $q_{\mathrm{m}}(\mathrm{mg} / \mathrm{g})$ & 86.59 & 123.47 & 186.31 & 372.94 \\
\hline & & $E_{\mathrm{a}}(\mathrm{KJ} / \mathrm{mol})$ & 19.74 & 28.24 & 64.09 & 35.88 \\
\hline & & $R^{2}$ & 0.772 & 0.898 & 0.766 & 0.748 \\
\hline
\end{tabular}




\subsection{Thermodynamics of Adsorption}

To understand the effect of temperature on the adsorption capacity of the CDM-HCP towards anilines, the results are discussed for the different temperatures. The changes in thermodynamic parameters, including enthalpy change $(\Delta H)$, entropy change $(\Delta S)$, and Gibbs free energy change $(\Delta G)$, were calculated by $K_{\mathrm{L}}$ at the different temperatures and were fitted based on the isothermal equation and the van' $t$ Hoff equation. The results are given in the Supplementary Materials. The thermochemical data for the retention of anilines onto the CDM-HCP are listed in Table S2 (Supplementary Materials).

As shown in Table S2 (Supplementary Materials), $\Delta H$ values were negative, demonstrating that the adsorption process was of an exothermic nature. Moreover, the negative $\Delta G$ also implied that the adsorption was a spontaneous process. The increase of $\Delta G$ with temperature increasing indicated that the adsorption of anilines was more beneficial at lower temperatures. Furthermore, the negative $\Delta S$ showed that the adsorption was an entropy reduction process, which might occur because a large number of anilines were adsorbed onto the adsorbent.

\subsection{Regeneration Test}

The regeneration of adsorbent is crucial for the adsorption process because it can lower the adsorption cost by recovering its adsorption performance from aqueous solutions. Desorption and regeneration experiments were studied for five cycles (Figure S5 (Supplementary Materials)), implying that the desorption process with methanol and $\mathrm{HCl}$ solution was efficient, and the saturated absorption capacity can attain 95-99\% of virgin CDM-HCP. The results confirmed that the CDM-HCP could be efficiently recovered and it exhibited a good regeneration property. The adsorption capacity of the CDM-HCP was higher than some commercial polymeric adsorbents, such as XAD-4, PA66, and AB-8 (Table S3 (Supplementary Materials)). It showed that the CDM-HCP is a promising adsorbent in the removal of organic pollutants.

\subsection{Adsorption Mechanism}

To deduce the adsorption mechanism, FTIR spectra of the CDM-HCP and the CDM-HCP after adsorption of anilines were compared (Figure 10).

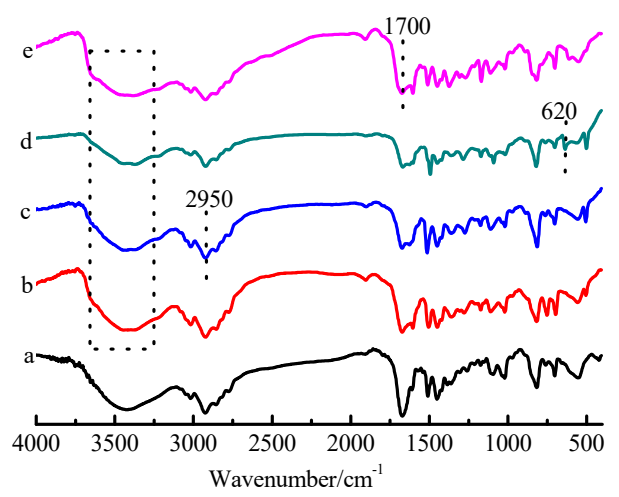

Figure 10. FTIR spectra of the CDM-HCP before and after metal adsorption: CDM-HCP (a), CDM-HCP-aniline (b), CDM-HCP- $p$-MA (c), CDM-HCP- $p$-CA (d), and CDM-HCP- $p$-ABC (e).

For the FTIR spectra in Figure 10b-e, the broad peak in the region of $3300-3500 \mathrm{~cm}^{-1}$ was due to the -OH stretching mode of $\beta$-CD. The peak intensity weakened slightly and the frequency red-shifted after adsorption of the anilines, implying that there were strong affinities between the CDM-HCP and the anilines. The results demonstrated that the interaction between the functional groups of $\beta$-CD with the anilines is formed during the adsorption process. To gain further insight into the adsorption mechanism, Figure 11 shows the changes in the composition of the CDM-HCP before and after adsorption. 

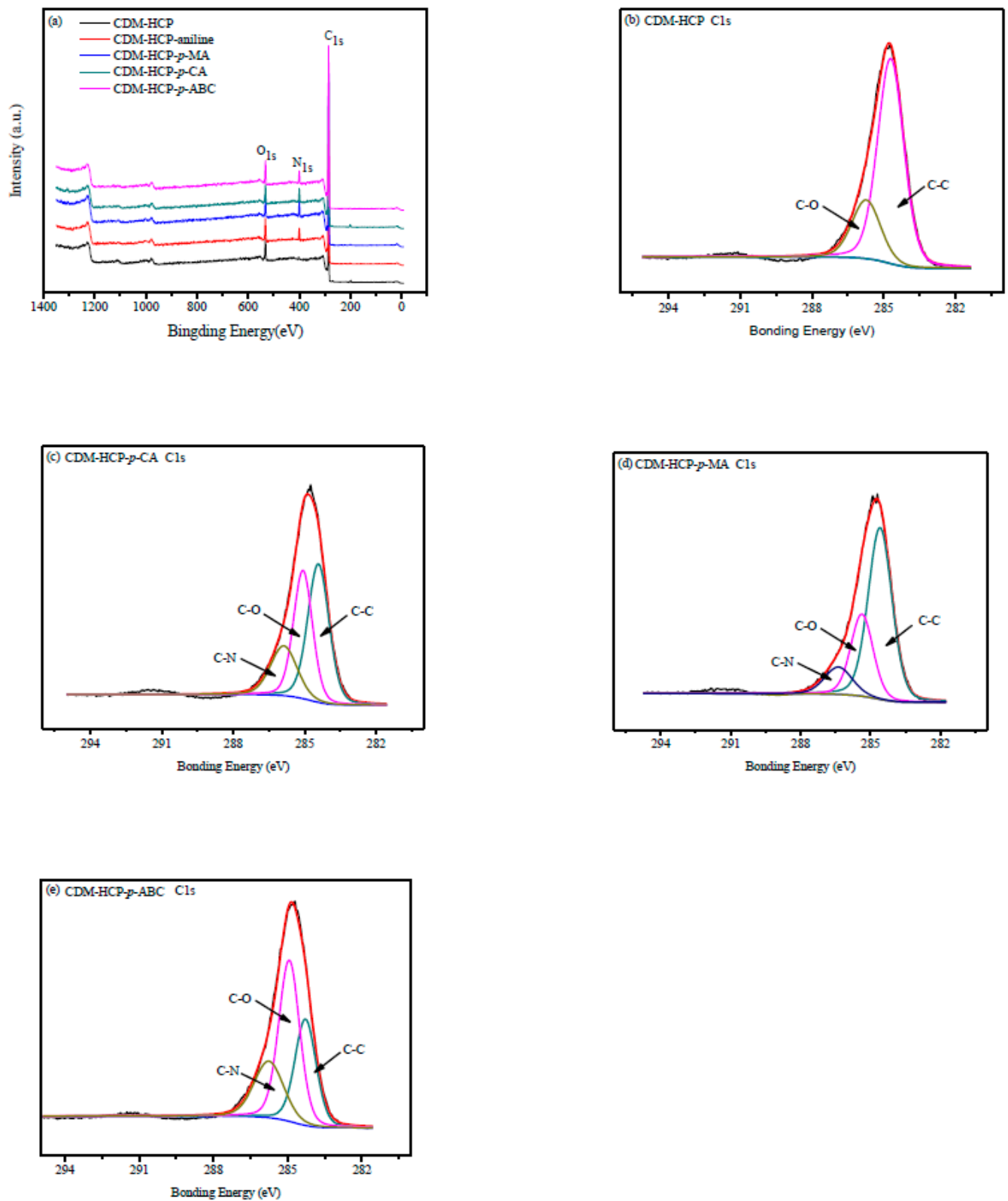

Figure 11. High-resolution XPS spectra of the CDM-HCP (a) and C 1s (b-e) before and after aniline adsorption.

As shown in Figure 11, the two peaks around $284.7 \mathrm{eV}$ and $532 \mathrm{eV}$ belong to $\mathrm{C} 1 \mathrm{~s}$ and $\mathrm{O} 1 \mathrm{~s}$, respectively. The new peaks of N1s were observed at $400 \mathrm{eV}$, which may be attributed to the adsorption by anilines, leading to an increase in nitrogen-containing functional groups. The typical $\mathrm{C}_{1 \mathrm{~s}}$ XPS spectra of the CDM-HCP with and without adsorbing anilines are displayed in Figure 11b-e. Before adsorption, the peaks at 284.2 and $285.4 \mathrm{eV}$ for the value states of the CDM-HCP were due to the presence of $\mathrm{C}=\mathrm{C}$ and $\mathrm{C}-\mathrm{O}$, respectively. However, a new peak due to $\mathrm{C}-\mathrm{N}$ appeared at $286.7 \mathrm{eV}$, which further proves the adsorption of anilines [35]. The discrete Fourier transform (DFT) method was also used to demonstrate that $\beta$-CD can form stable complexes with anilines, as shown in Figure S6 (Supplementary Materials). Table S4 (Supplementary Materials) shows the calculated $B E$ for $\beta$-CD/anilines with orientations head down and head up by PM3. The negative binding energies indicated that $\beta$-CD could interact with anilines to form stable inclusion complexes. The results calculated by ONIOM2 (B3LYP/6-31G(d):PM3) also followed the same trend as those from PM3. The BE from the ONIOM2 calculations for the 
$\beta$ - $\mathrm{CD} / p-\mathrm{ABC}$ head down, $\beta$-CD $/ p$-CA head up, $\beta$ - $\mathrm{CD} / p$-MA head up, and $\beta$-CD/aniline head up were $-145.79 \pm 2.45,-122.47 \pm 1.63,-86.09 \pm 1.14$, and $-78.10 \pm 0.89 \mathrm{kJmol}^{-1}$, respectively. They showed that stability of the inclusion complexes followed the sequence of $\beta-\mathrm{CD} / p-\mathrm{ABC}>\beta-\mathrm{CD} / p-\mathrm{CA}>\beta-\mathrm{CD} / p-\mathrm{MA}>$ $\beta$-CD/aniline, which may lead to the different adsorption capacity. Optimized structures calculated by ONIOM2 also indicated that $\beta$-CD can form stable complexes with anilines via the $\mathrm{O}-\mathrm{H} \cdots \mathrm{O}$ hydrogen bond, as shown in Figure S7 and Table S5 (Supplementary Materials). It was clear that the significantly enhanced adsorption of anilines on the CDM-HCP was mainly driven by hydrogen bonding between adsorbent and adsorbate. Hydrophobic interactions and $\pi-\pi$ stacking attractions also played an important role in the aniline adsorption (Figure 12).

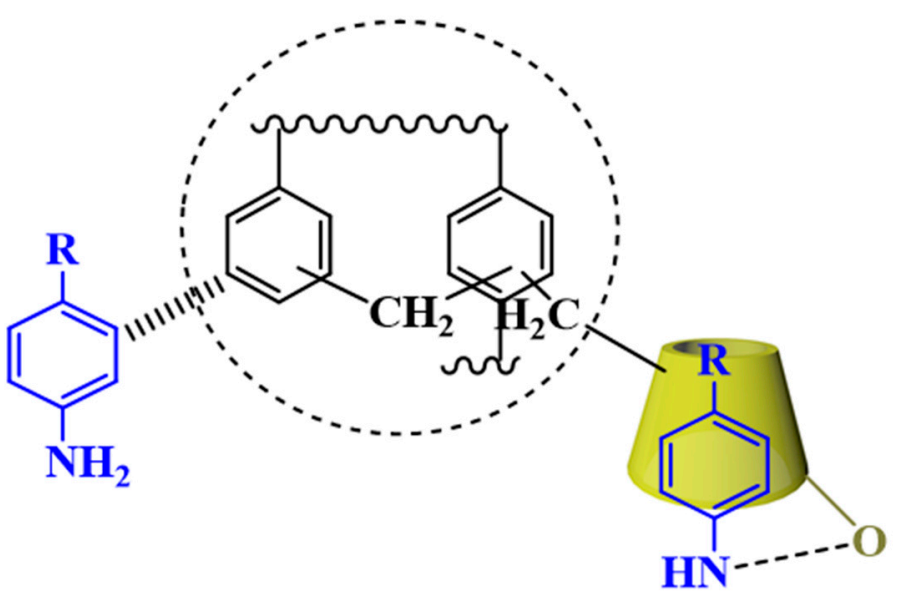

\section{$\mathrm{R}=\mathrm{H}, \mathrm{CH}_{3}, \mathrm{Cl}$ or $\mathrm{COOH}$}

Figure 12. Schematic mechanism of the adsorption of anilines with the CDM-HCP.

\section{Conclusions}

In the present study, a simple and efficient method for the synthesis of a $\beta$-cyclodextrin-modified hyper-crosslinked resin (CDM-HCP) was presented. It was used to study the removal of anilines from waste effluents. The optimum process, such as amount of $\beta-\mathrm{CD}$ in the CDM-HCP, $\mathrm{pH}$, ionic strength, and temperature of the solution was investigated for the improvement of aniline adsorption. The maximum adsorption capacities of the CDM-HCP were nearly $148.97 \mathrm{mg} \cdot \mathrm{g}^{-1}$ for aniline, $198.45 \mathrm{mg} \cdot \mathrm{g}^{-1}$ for $p$-methylaniline, $293.71 \mathrm{mg} \cdot \mathrm{g}^{-1}$ for $p$-chloroaniline, and $622.91 \mathrm{mg} \cdot \mathrm{g}^{-1}$ for $p$-aminobenzoic acid, which are higher than some commercial polymeric adsorbents, such as XAD-4, PA66, and AB-8. Aniline adsorption followed the pseudo-second-order kinetic model better. The adsorption isotherms of $p$-MA and $p$-ABC were fitted to the Langmuir model better, whereas aniline and $p$-CA obeyed the Freundlich model better. Moreover, regeneration experiments indicated that the adsorption performance after five cycles nearly attained that of the virgin adsorbent. The interaction mechanism, which was due to the synergistic effects of the weak interactions such as hydrogen bonding, hydrophobic interactions, and $\pi-\pi$ stacking attractions, was confirmed by FTIR, XPS, and the theoretical calculation. Briefly, the present adsorption material exhibited great potential for its application in water treatment.

Supplementary Materials: The following are available online at http://www.mdpi.com/2073-4360/12/7/1620/s1/.

Author Contributions: Methodology, investigation, and writing, Z.Y.; original draft preparation, G.W.; data curation and validation, Q.L.; data curation, funding acquisition, writing-review and editing, H.A. and X.Y.; project administration, H.J. All authors have read and agreed to the published version of the manuscript.

Funding: This work was preliminarily supported financially by the National Natural Science Foundation of China (2191101377, 21425627, 31700470), the National Natural Science Foundation of China-SINOPEC Joint fund (U1663220), the Natural Science Foundation of Guangdong Province (2017A030313057), and the Guangdong Technology Research Center for Synthesis and Separation of Thermosensitive Chemicals (2015B090903061). 
Conflicts of Interest: The authors declare no conflict of interest.

\section{References}

1. Cai, J.G.; Li, A.M.; Shi, H.Y.; Feng, Z.H.; Long, C.; Zhang, Q.X. Equilibrium and kinetic studies on the adsorption of aniline compounds from aqueous phase onto bifunctional polymeric adsorbent with sulfonic groups. Chemosphere 2005, 61, 502-509.

2. Chen, H.; Wang, C.; Li, H.; Ma, R.; Yu, Z.; Li, L.; Xiang, M.; Chen, X.; Hua, X.; Yu, Y. A review of toxicity induced by persistent organic pollutants (POPs) and endocrine-disrupting chemicals (EDCs) in the nematode caenorhabditis elegans. J. Environ. Manag. 2019, 237, 519-525. [CrossRef] [PubMed]

3. Liang, H.Y.; Zhang, Y.Q.; Huang, S.B.; Hussain, I. Oxidative degradation of p-chloroaniline by copper oxidate activated persulfate. Chem. Eng. J. 2013, 218, 384-391. [CrossRef]

4. Xu, H.; Zhao, X.S.; Huang, S.B.; Li, H.; Tong, N.; Wen, X.Y.; Sun, C.C.; Fazal, S.; Zhang, Y.Q. Evaluation of microbial p-chloroaniline degradation in bioelectrochemical reactors in the presence of easily-biodegrading cosubstrates: Degradation efficiency and bacterial community structure. Bioresource. Technol. 2018, 270, 422-429. [CrossRef]

5. Chen, C.Y.; Geng, X.H.; Huang, W.L. Adsorption of 4-chlorophenol and aniline by nanosized activated carbons. Chem. Eng. J. 2017, 327, 941-952. [CrossRef]

6. Dewage, N.B.; Liyanage, A.S.; Smith, Q.; Pittman, C.U.J.; Perez, F.; Hassan, E.B.; Mohan, D.; Mlsna, T. Fast aniline and nitrobenzene remediation from water on magnetized and nonmagnetized Douglas fir biochar. Chemosphere 2019, 225, 943-953. [CrossRef]

7. Jin, Q.; Hu, Z.C.; Jin, Z.F.; Qiu, L.Q.; Zhong, W.H.; Pan, Z.Y. Biodegradation of aniline in an alkaline environment by a novel strain of the halophilic bacterium, Dietzia natronolimnaea JQ-AN. Bioresour. Technol. 2012, 117, 148-154. [CrossRef]

8. Ma, G.; Lu, J.L.; Meng, Q.G.; Lv, H.Q.; Shui, L.L.; Zhang, Y.G.; Jin, M.L.; Chen, Z.H.; Yuan, M.Z.; Nötzel, R.; et al. Synergistic effect of $\mathrm{Cu}$-ion and $\mathrm{WO}_{3}$ nanofibers on the enhanced photocatalytic degradation of Rhodamine B and aniline solution. Appl. Surf. Sci. 2018, 451, 306-314. [CrossRef]

9. Chen, C.; Jia, N.; Song, K.J.; Zheng, X.; Lan, Y.Q.; Li, Y. Sulfur-doped copper-yttrium bimetallic oxides: A novel and efficient ozonation catalyst for the degradation of aniline. Sep. Purif. Technol. 2019, 236, 116248. [CrossRef]

10. Kuang, W.; Liu, Y.N.; Huang, J.H. Phenol-modified hyper-cross-linked resins with almost all micro/mesopores and their adsorption to aniline. J. Colloid Interface Sci. 2017, 487, 31-37. [CrossRef]

11. Wang, X.M.; Mao, X.; Huang, J.H. Hierarchical porous hyper-cross-linked polymers modified with phenolic hydroxyl groups and their efficient adsorption of aniline from aqueous solution. Colloids Surf. A 2018, 558, 80-87. [CrossRef]

12. Gan, Y.Q.; Chen, G.; Sang, Y.F.; Zhou, F.; Man, R.L.; Huang, J.H. Oxygen-rich hyper-cross-linked polymers with hierarchical porosity for aniline adsorption. Chem. Eng. J. 2019, 368, 29-36. [CrossRef]

13. Shao, L.; Huang, J. N-vinylimidazole-modified hyper-cross-linked resins with controllable porosity and polarity and their efficient adsorption towards p-nitrophenol from aqueous solution. J. Colloid Interface Sci. 2017, 507, 42-50. [CrossRef] [PubMed]

14. Li, Y.; Long, C.; Tao, W.H.; Li, A.M.; Zhang, Q.X. Fractal Dimensions of Macroporous and Hypercrosslinked Polymeric Adsorbents from Nitrogen Adsorption Data. J. Chem. Eng. Data 2010, 55, 3147-3150. [CrossRef]

15. Zhang, W.M.; Hong, C.H.; Pan, B.C.; Xu, Z.W.; Zhang, Q.J.; Lv, L. Removal enhancement of 1-naphthol and 1-naphthylamine in single and binary aqueous phase by acid-basic interactions with polymer adsorbents. J. Hazard. Mater. 2008, 158, 293-299. [CrossRef]

16. Uekama, K.; Hirayama, F.; Irie, T. Cyclodextrin drug carrier systems. Chem. Rev. 1998, 98, $2045-2076$. [CrossRef]

17. Connors, K.A. The stability of cyclodextrin complexes in solution. Chem. Rev. 1997, 97, 1325-1358. [CrossRef]

18. Panda, S.K.; Schrader, W.; Andersson, J.T. $\beta$-Cyclodextrin as a stationary phase for the group separation of polycyclic aromatic compounds in normal-phase liquid chromatography. J. Chromatogr. A 2006, 1122, 88-96. [CrossRef] 
19. Li, J.Q.; Geng, S.; Wang, Y.; Lv, Y.H.; Wang, H.B.; Liu, B.G.; Liang, G.Z. The interaction mechanism of oligopeptides containing aromatic rings with $\beta$-cyclodextrin and its derivatives. Food Chem. 2019, 286, 441-448. [CrossRef]

20. Morin-Crini, N.; Winterton, P.; Fourmentin, S.; Wilson, L.D.; Fenyvesi, É.; Crini, G. Water-insoluble $\beta$-cyclodextrin-epichlorohydrin polymers for removal of pollutants from aqueous solutions by sorption processes using batch studies: A review of inclusion mechanisms. Prog. Polym. Sci. 2018, 78, 1-23. [CrossRef]

21. Morin-Crini, N.; Crini, G. Environmental applications of water-insoluble $\beta$-cyclodextrin-epichlorohydrin polymers. Prog. Polym. Sci. 2013, 38, 344-368. [CrossRef]

22. Li, X.M.; Zhou, M.J.; Jia, J.X.; Ma, J.T.; Jia, Q. Design of a hyper-crosslinked $\beta$-cyclodextrin porous polymer for highly efficient removal toward bisphenol a from water. Sep. Purif. Technol. 2018, 195, 130-137. [CrossRef]

23. Li, H.Y.; Meng, B.; Chai, S.H.; Liu, H.L.; Dai, S. Hyper-crosslinked $\beta$-cyclodextrin porous polymer: An adsorption-facilitated molecular catalyst support for transformation of water-soluble aromatic molecules. Chem. Sci. 2016, 7, 905-909. [CrossRef] [PubMed]

24. Oh, C.G.; Ahn, J.H.; Ihm, S.K. Adsorptive removal of phenolic compounds by using hypercrosslinked polystyrenic beads with bimodal pore size distribution. React. Funct. Polym. 2003, 57, 103-111. [CrossRef]

25. Fischer, J.B.; Miller, J.H. Ion chromatography as an alternative to standard methods for analysis of macro-nutrients in Mehlich 1 extracts of unfertilized forest soils. Commun. Soil Sci. Plant Anal. 2004, 35, 2191-2208. [CrossRef]

26. Nguyen, N.T.; Dao, T.H.; Truong, T.T.; Nguyen, T.M.T.; Pham, T.D. Adsorption characteristic of ciprofloxacin antibiotic onto synthesized alpha alumina nanoparticles with surface modification by polyanion. J. Mol. Liq. 2020, 113150. [CrossRef]

27. Pham, T.T.; Tran, T.T.; Le, V.A.; Pham, T.T.; Dao, T.H.; Le, T.S. Adsorption characteristics of molecular oxytetracycline onto alumina particles: The role of surface modification with an anionic surfactant. J. Mol. Liq. 2020, 110990. [CrossRef]

28. Yang, Z.J.; Chai, K.G.; Ji, H.B. Selective inclusion and separation of cinnamaldehyde and benzaldehyde by insoluble $\beta$-cyclodextrin polymer. Sep. Purif. Technol. 2011, 80, 209-216. [CrossRef]

29. Yang, Z.J.; Zeng, H.; Zhou, X.T.; Ji, H.B. Mechanism into selective oxidation of cinnamaldehyde using $\beta$-cyclodextrin polymer as phase-transfer catalyst. Tetrahedron 2012, 68, 5912-5919. [CrossRef]

30. Yang, Z.J.; Xiao, Z.B.; Ji, H.B. Solid inclusion complex of terpinen-4-ol/ $\beta$-cyclodextrin: Kinetic release, mechanism and its antibacterial activity. Flavour. Frag. J. 2015, 30, 179-187. [CrossRef]

31. Wang, X.M.; Zhang, T.; Huo, J.Q.; Huang, J.H.; Liu, Y.N. Tunable porosity and polarity of polar post-cross-linked resins and selective adsorption. J. Colloid Interface Sci. 2017, 487, 231-238. [CrossRef] [PubMed]

32. Yang, Z.J.; Huang, X.N.; Yao, X.D.; Ji, H.B. Thiourea modified hyper-crosslinked polystyrene resin for heavy metal ions removal from aqueous solutions. J. Appl. Polym. Sci. 2018, 135, 45568. [CrossRef]

33. Huang, J.H.; Zha, H.W.; Jin, X.Y.; Deng, S.G. Efficient adsorptive removal of phenol by a diethylenetriaminemodified hypercrosslinked styrene-divinylbenzene (PS) resin from aqueous solution. Chem. Eng. J. 2012, 195-196, 40-48. [CrossRef]

34. Yang, Z.J.; Liu, J.P.; Yao, X.D.; Rui, Z.B.; Ji, H.B. Efficient removal of BTEX from aqueous solution by $\beta$-cyclodextrin modified poly (butyl methacrylate) resin. Sep. Purif. Technol. 2016, 158, 417-421. [CrossRef]

35. Lu, K.; Chai, K.G.; Liang, Q.H.; Xu, Z.J.; Li, G.Y.; Ji, H.B. Biosorption and selective separation of acetophenone and 1-phenylethanol with polysaccharide-based polymers. Chem. Eng. J. 2017, 317, 862-872. [CrossRef]

36. Liu, G.L.; Wang, Y.X.; Shen, C.J.; Ju, Z.F.; Yuan, D.Q. A facile synthesis of microporous organic polymers for efficient gas storage and separation. J. Mater. Chem. A 2015, 3, 3051-3058. [CrossRef]

37. Huang, J.H.; Jin, X.Y.; Mao, J.L.; Yuan, B.; Deng, R.J.; Deng, S.G. Synthesis, characterization and adsorption properties of diethylenetriamine-modified hypercrosslinked resins for efficient removal of salicylic acid from aqueous solution. J. Hazard. Mater. 2012, 217-218, 406-415. [CrossRef]

38. Li, K.R.; Zhou, M.H.; Liang, L.; Jiang, L.L.; Wang, W. Ultrahigh-surface-area activated carbon aerogels derived from glucose for high-performance organic pollutants adsorption. J. Colloid Interface Sci. 2019, 546, 333-343. [CrossRef]

39. Fu, Y.J.; Zu, Y.G.; Liu, W.; Hou, C.L.; Chen, L.Y.; Li, S.M.; Shi, X.G.; Tong, M.H. Preparative separation of vitexin and isovitexin from pigeonpea extracts with macroporous resins. J. Chromatogr. A 2007, 1139, $206-213$. [CrossRef] 
40. Wang, Y.F.; Mao, F.F.; Wei, X.L. Characterization and antioxidant activities of polysaccharides from leaves, flowers and seeds of green tea. Carbohydr. Polym. 2012, 88, 146-153. [CrossRef]

41. Yu, F.; Wu, Y.Q.; Li, X.M.; Ma, J. Kinetic and thermodynamic studies of Toluene, Ethylbenzene, and m-Xylene adsorption from aqueous solutions onto $\mathrm{KOH}$-activated multiwalled carbon nanotubes. J. Agric. Food Chem. 2012, 60, 12245-12253. [CrossRef] [PubMed]

Sample Availability: Samples of the compounds are available from the authors.

(C) 2020 by the authors. Licensee MDPI, Basel, Switzerland. This article is an open access article distributed under the terms and conditions of the Creative Commons Attribution (CC BY) license (http://creativecommons.org/licenses/by/4.0/). 